\title{
IMPROVING THE DESIGN OF LOW VOLUME SEALED ROADS IN TANZANIA
}

\author{
David A. Mfinanga and Lusekelo A. Mwakyami \\ Department of Transportation and Geotechnical Engineering \\ University of Dar es Salaam, P.O. Box 35131, Dar es Salaam, Tanzania \\ Tel: 0713-329690 Fax: 2410078 \\ E-mail:mfinanga@ce.udsm.ac.tz
}

\begin{abstract}
The main objective of the study was to identify appropriate road designs for Low Volume Sealed Roads (LVSRs) with the aim of improving the design of such roads in Tanzania. The study was conducted in Dar es Salaam and Morogoro regions in Tanzania where data for LVSRs were collected from primary and secondary sources in the two regions. The study found that by using an improved pavement design method specifically meant for LVSRs results in cost savings for LVSRs of up to 51\% compared with the conventional method of pavement design in Tanzania. The study recommends that the pavement design method for lightly trafficked sealed roads in southern Africa developed by Transport Research Laboratory, which was found to be most cost-effective, be used to design (or develop a procedure for design of) LVSRs in Tanzania and that the roads be preferably sealed with Otta seal or Surface dressing. The study also recommends that LVSRs in Tanzania be defined by a maximum traffic volume of $400 \mathrm{vpd}$.
\end{abstract}

Keywords: low-volume roads, low-volume sealed roads, pavement design

\subsection{Introduction}

The road network in Tanzania which is estimated at around $85,000 \mathrm{~km}$, provides the dominant mode of freight and passenger transport and thus plays a vital role in the economy of the country. The Prime Minister's office - Regional Administration and Local Governments (PMO-RALG) and the Tanzania National Roads Agency (TANROADS) indicates that currently about $93 \%$ of the road length is unpaved with only $7 \%$ being paved including both the national and district road networks. The substantial length of unsurfaced particularly low volume roads in Tanzania is becoming increasingly difficult to sustain and impose a logistical, technical and financial burden on most road agencies due to constraints on physical, human, financial and natural resources. These roads require the continuous use of a non-renewable resource (gravel) which is being seriously depleted in many regions and is causing serious environmental problems in the process.

In general, low volume roads are built to lower standard than high volume roads, carry a small fraction of the total traffic, but serve the majority of the predominantly rural and urban population in the country and therefore play a very important economic and social role. They enable rural communities to grow and market their agricultural products more efficiently, and they ease access to alternative income sources. Low volume roads increase access to school, health facilities, recreation and other social activities that promote well being of the community (Benmaamar 2003).

The objective of pavement design is to provide an economic structure in terms of material types and thickness that can withstand the expected traffic loading over a specified time, without deteriorating below a predetermined level of service. This provides a particular challenge for designers as the existing methods of pavement design, even those developed in the SADC region, generally cater for relatively high volumes of traffic on the assumption that traffic load is the major cause of deterioration. As a result, such methods are often inappropriate for application to LVSRs for which the environmentally induced rather than load-associated distress determines pavement performance (Gourley and Greening 1999). Thus, there is a need to be very discerning in the application of current pavement design methodologies and to adapt them, where necessary, to suit the prevailing conditions of climate, materials, traffic loading and other related factors in LVSRs.

Technology, research and knowledge about Low Volume Sealed Roads (LVSRs) have 
advanced significantly in the SADC region resulting in much acceptance of the wisdom on the LVSRs provision and the clear need to revise conventional approaches (SATCC, 2003). In spite of research conducted in the SADC region to develop approaches, standards and specifications which are relevant to the needs of road infrastructure in the region, relatively little of the results of this research have been put in practice. In many countries, the fundamental approach to LVSRs provision has remained unchanged in the past 20 to 30 years.

In Tanzania, LVSRs are constructed using standard pavement structures that were not specifically meant for them. The current Tanzanian Pavement and Material Design Manual (MoW 1999) does not explicitly consider LVSRs leading to inappropriate designs in such cases. The aim of this research is therefore to identify and recommend costeffective approaches to the design of LVSRs from a technical and economic point of view.

\subsection{Literature Review}

The Transport Research Laboratory (TRL) in collaboration with a number of road authorities and consultant partners have been engaged in extensive studies on the performance of lowvolume sealed roads within southern Africa since 1994. The roads included in-service primary and secondary roads with ages varying from thirty years old to relatively new roads and specially constructed experimental sections. The roads which were studied were located in Botswana, Malawi, Zambia and Zimbabwe. Fifty seven (57) trial sections were established on the road networks in Malawi, Botswana and Zimbabwe. The primary objectives of the studies were to derive costeffective pavement materials and design standards which promote greater use of local resources; to produce calibrated road deterioration relationship for these categories of roads taking full account of important design and construction parameters; and to justify improvements to current practice from a technical and economic view point (Gourley et al, 2001).

In recognition of the need for raising awareness of recent developments and current knowledge in the provision of rural roads, the British Department for International Development (DFID), the Norwegian Agency for Development Co-operation (NORAD) and the Swedish International Development Agency (SIDA) agreed to fund the provision of a "guideline on low-volume sealed roads in the SADC region". The guideline was commissioned by Southern Africa Transport and Communication Commission (SATCC) and TRL was appointed to manage the project in association with the Norwegian Public Roads Administration (NPRA), road departments and agencies and other research organizations and consultancies in southern Africa. The main purpose of the guideline was to provide stakeholders with a synthesis of best regional and international practice in all aspects of low volume sealed roads. In so doing, it is expected to correct shortcomings of other available guidelines and manuals that tend to be more narrowly focused on the technical aspects of relatively more heavily trafficked roads and, as a result, have limited applicability to low volume sealed roads (SATCC, 2003).

The Design methods used in SADC region as presented in table 1 are considered suitable for low-volume roads. However, they should be used flexibly rather than prescriptively.

Table 1: Pavement design methods appropriate for use in the SADC region

\begin{tabular}{|l|l|}
\hline Mechanistic-Empirical Methods & Empirical Methods \\
\hline \hline S - N Method (1993) & DCP METHOD (1984) \\
\hline TRH4 (1996) & SATCC Pavement Design Guide (1997) \\
\hline \multirow{2}{*}{} & TRL ORN 31 (1993) \\
\cline { 2 - 2 } & TRL/SADC Pavement Design Guide (1999) \\
\hline
\end{tabular}

Source: SADC guideline on low-volume sealed roads, 2003 
In addition to above generic design methods, the SADC guideline also mentioned prominent guides/manuals in the region which are country specific such as Zimbabwe Pavement Design Guide (1975), Botswana Roads Design Manual (1982) and Tanzania Pavement and Material Design Manual (1999).

\subsection{Approach and Methodology}

The study was carried out from August, 2007 to April, 2008 on LVSRs in Dar es Salaam (DSM) and Morogoro regions with the major aim of improving the design of LVSRs in Tanzania by identifying appropriate designs. Specifically, the study was intending to establish the state of the practice of low volume sealed roads in
Tanzania, compare the currently designed pavement structures for LVSR with those resulting from the use of relevant LVSRs design procedures, and eventually recommend appropriate procedures for cost-effective design of LVSRs.

This study covered 144 LVSRs in Dar es Salaam and Morogoro regions with a total length of $240.7 \mathrm{~km}$ carrying traffic not exceeding $500 \mathrm{vpd}$. These two regions whose areas are of moderate climate were taken to represent Tanzania whose area is also mostly of moderate climate. A summary of the extent of LVSR in the study area is shown in table 2.

Table 2: Extent of LVSRs in Dar es Salaam (DSM) and Morogoro regions

\begin{tabular}{|l|l|l|l|l|l|}
\hline $\begin{array}{l}\text { Road Authority in } \\
\text { DSM Region }\end{array}$ & $\begin{array}{l}\text { Length of } \\
\text { LVSRs } \\
\mathbf{( k m )}\end{array}$ & $\begin{array}{l}\text { No. of } \\
\text { LVSRs }\end{array}$ & $\begin{array}{l}\text { Road Authority in } \\
\text { Morogoro Region }\end{array}$ & $\begin{array}{l}\text { Length of } \\
\text { LVSRs (km) }\end{array}$ & $\begin{array}{l}\text { No. of } \\
\text { LVSRs }\end{array}$ \\
\hline \hline DSM TANROADS & 32.06 & 18 & $\begin{array}{l}\text { Morogoro } \\
\text { TANROADS }\end{array}$ & 78.00 & 14 \\
\hline $\begin{array}{l}\text { Kinondoni } \\
\text { Municipal Council }\end{array}$ & 58.24 & 39 & $\begin{array}{l}\text { Morogoro Municipal } \\
\text { Council }\end{array}$ & 12.01 & 7 \\
\hline $\begin{array}{l}\text { Ilala Municipal } \\
\text { Council }\end{array}$ & 48.28 & 50 & & - & - \\
\hline $\begin{array}{l}\text { Temeke Municipal } \\
\text { Council }\end{array}$ & 12.07 & 16 & - & - & - \\
\hline Total & $\mathbf{1 5 0 . 6 5}$ & $\mathbf{1 2 3}$ & Total & $\mathbf{9 0 . 0 1}$ & $\mathbf{2 1}$ \\
\hline
\end{tabular}

TANROADS = Tanzania National Roads Agency

Source: Dar es Salaam and Morogoro regions road authorities

The activities carried out were to identify constructed LVSRs in the study areas, their length and traffic volumes (ADT); determine design traffic, soil condition and designed pavement structures; compare the designed structure with that of relevant LVSR procedures; analyse results and recommend on approapriate approach; and develop the definition of LVSR in Tanzania.

\subsection{Findings and Discussion of the Results}

\subsection{ADT in LVSRs}

The analysis of the studied 144 road segments shows that the majority of these roads fall in the traffic volume ranging between 0 and 200 vpd followed by the roads with traffic volume within the range of 201-300, 301-400 and finally 401-500 vpd as shown in figure 1 . 


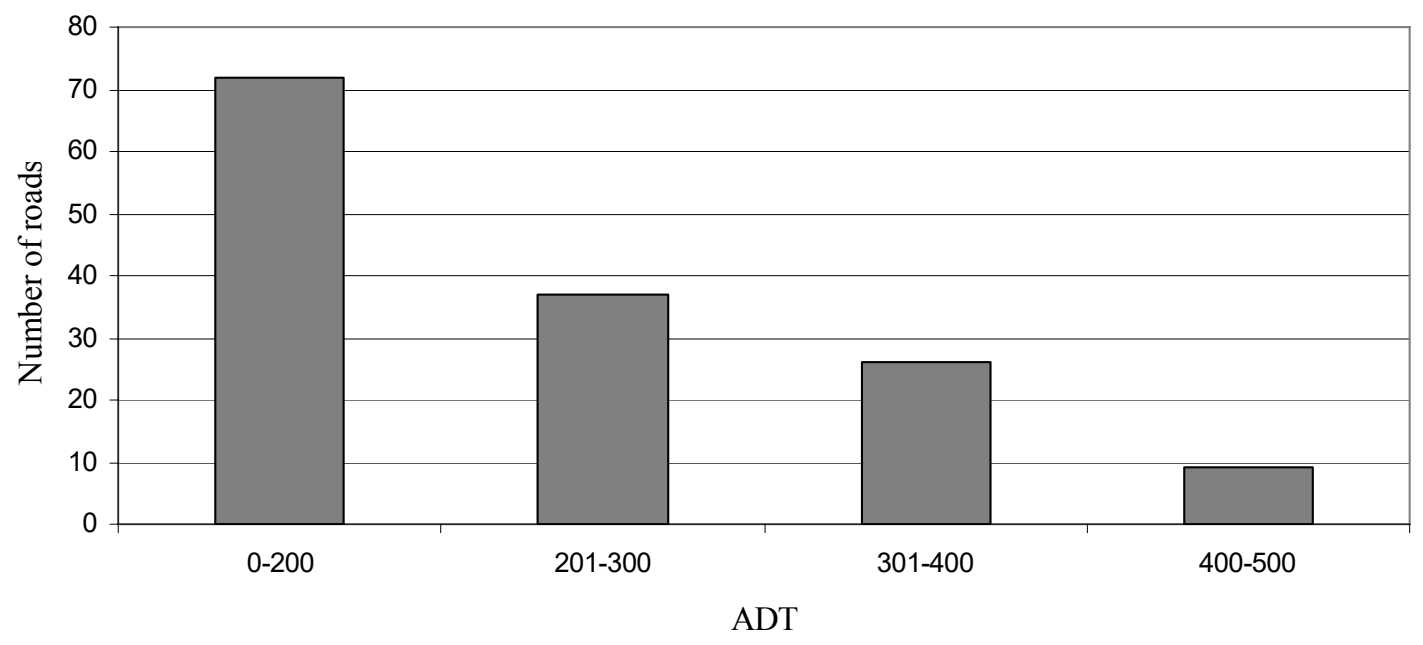

Figure 1: Number of roads in different ADT ranges

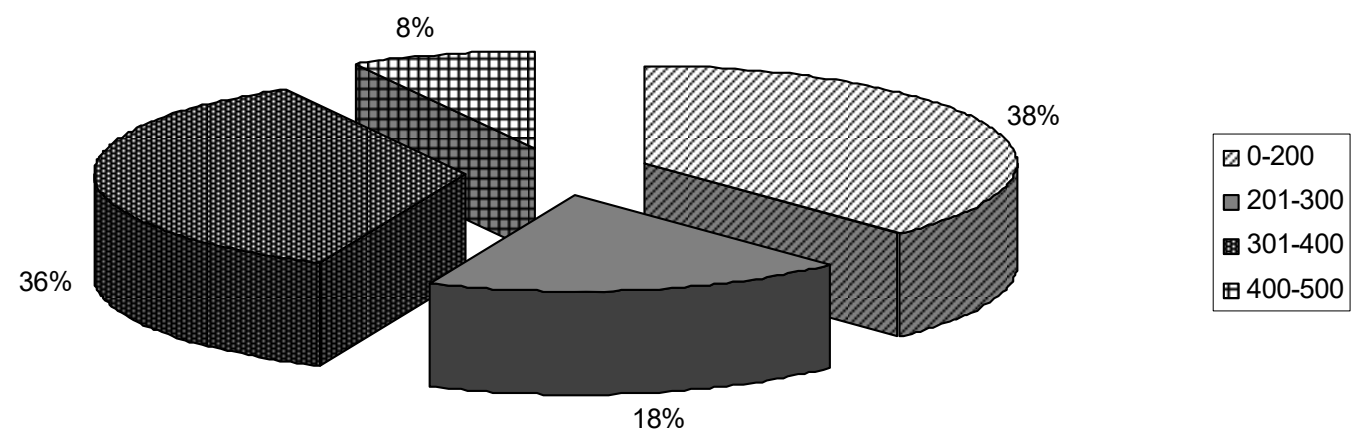

Figure 2: Percentage road length with different ADTs

Further analysis was also carried out to relate the traffic volume with road length as shown in figure 2. A higher percentage of the studied low volume road network length falls on the roads with ADT ranging from 0 to 200 followed by roads with an ADT range of 301-400, 201-300 and finally 401-500. The results obtained from both analyses in figures 1 and 2, provide some basis for setting an upper limit of traffic volume for LVSRs in Tanzania.

\subsection{Heavy Vehicles in LVSRs}

The study conducted on nine district roads in Dar es Salaam to determine the category of heavy vehicles most plying the low volume sealed roads in Tanzania revealed that medium goods vehicle (MGV) category constitute a higher percentage of traffic loading on most LVSRs in Dar es Salaam when compared to other types of heavy vehicle categories (buses and $\mathrm{HGV}$ ) as presented in table 3 and figure 3 . 
Table 3: Percentage vehicle distribution in DSM roads by vehicle category

\begin{tabular}{|c|c|c|c|c|c|c|c|c|c|c|}
\hline 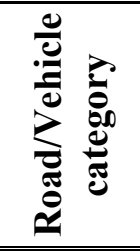 & & 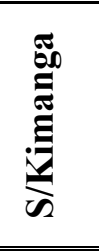 & 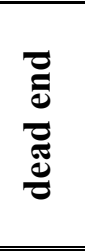 & 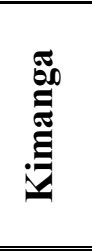 & 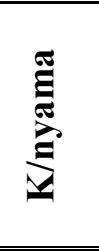 & $\underset{Z}{\stackrel{\Xi}{\Xi}}$ & $\stackrel{\text { }}{\stackrel{\Xi}{*}}$ & 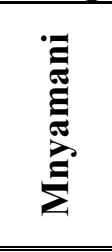 & 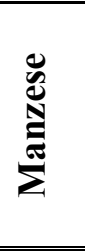 & 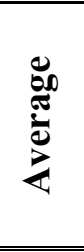 \\
\hline M/cycle & 5 & 3.2 & 9.3 & 4.5 & 2.9 & 7.9 & 6.3 & 3.9 & 6.9 & 5.5 \\
\hline Car & 29 & 27.6 & 43.2 & 28.6 & 46.4 & 46.1 & 42.9 & 37.75 & 40 & 38.0 \\
\hline LGV & 36.7 & 34.6 & 40 & 29.6 & 43.9 & 37.8 & 40.5 & 40.3 & 36 & 37.7 \\
\hline MGV & 5.7 & 6.1 & 4.8 & 4.9 & 2.5 & 3.3 & 5 & 4.1 & 4.8 & 4.6 \\
\hline HGV & 0.4 & 0.4 & 0.3 & 0.1 & 0.1 & 0.2 & 0.2 & 0.25 & 1.2 & 0.4 \\
\hline M/bus & 18 & 21.6 & 2 & 25.7 & 3 & 3.9 & 3.3 & 10.5 & 8.7 & 10.7 \\
\hline Buses & 5.2 & 6.5 & 0.4 & 6.6 & 1.2 & 0.8 & 1.8 & 3.2 & 2.4 & 3.1 \\
\hline Total & 100 & 100 & 100 & 100 & 100 & 100 & 100 & 100 & 100 & 100 \\
\hline
\end{tabular}

LGV=Light Goods Vehicle, MGV=Medium Goods Vehicle, HGV=Heavy Goods Vehicle

Source: Community Infrastructure Upgrading Project (CIUP) 2002, road project design report

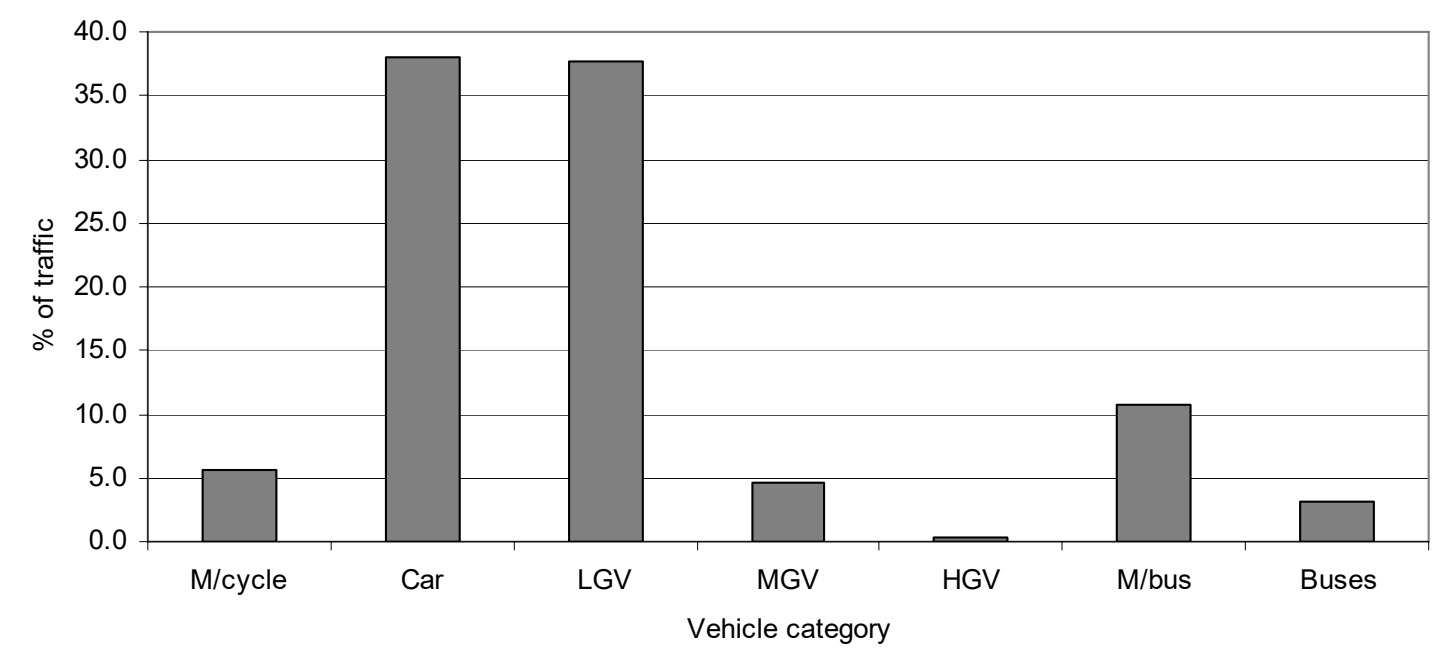

Figure 3: Vehicle category distribution on DSM roads

\subsection{Pavement Design Comparison}

Five pavement design methods among the ones recommended in the SADC guideline on LVSRs were further analysed so as to determine among them a cost-effective pavement design method for construction of low-volume sealed roads in Tanzania. These are Overseas Road Note 31 (ORN 31) (TRL 1993), Tanzania Pavement and Material Design Manual (PMDM) (MoW 1999), A structural design guide for low volume secondary and feeder roads in Zimbabwe (SDGLVSF) (Gourley et al. 1998), TRL developed design procedure for lightly trafficked sealed roads in southern Africa (TRL-LTSR) (Gourley 1997), and SATCC draft code of practice for the design of road pavements (SATCC) (SATCC 1998). Table 4 shows the total design depths obtained using the design methods for LVSRs. 
Table 4: Summary of design depths for different standards

\begin{tabular}{|l|c|c|c|c|c|}
\hline $\begin{array}{l}\text { Subgrade } \\
\text { CBR (\%) }\end{array}$ & ORN 31 & PMDM & SDGLVSFR & TRL-LTSR & SATCC \\
\hline \hline S1 $=2$ & 675 & 600 & 475 & 475 & 675 \\
\hline S2 $=3-4$ & 550 & 600 & 475 & 475 & 550 \\
\hline S3 $=5-7$ & 400 & 600 & 400 & 320 & 400 \\
\hline S4 $=8-14$ & 325 & 300 & 320 & 320 & 275 \\
\hline S5 $=15-29$ & 250 & 300 & 320 & 175 & 200 \\
\hline S6 $=30+$ & 150 & 300 & 175 & 150 & 100 \\
\hline
\end{tabular}

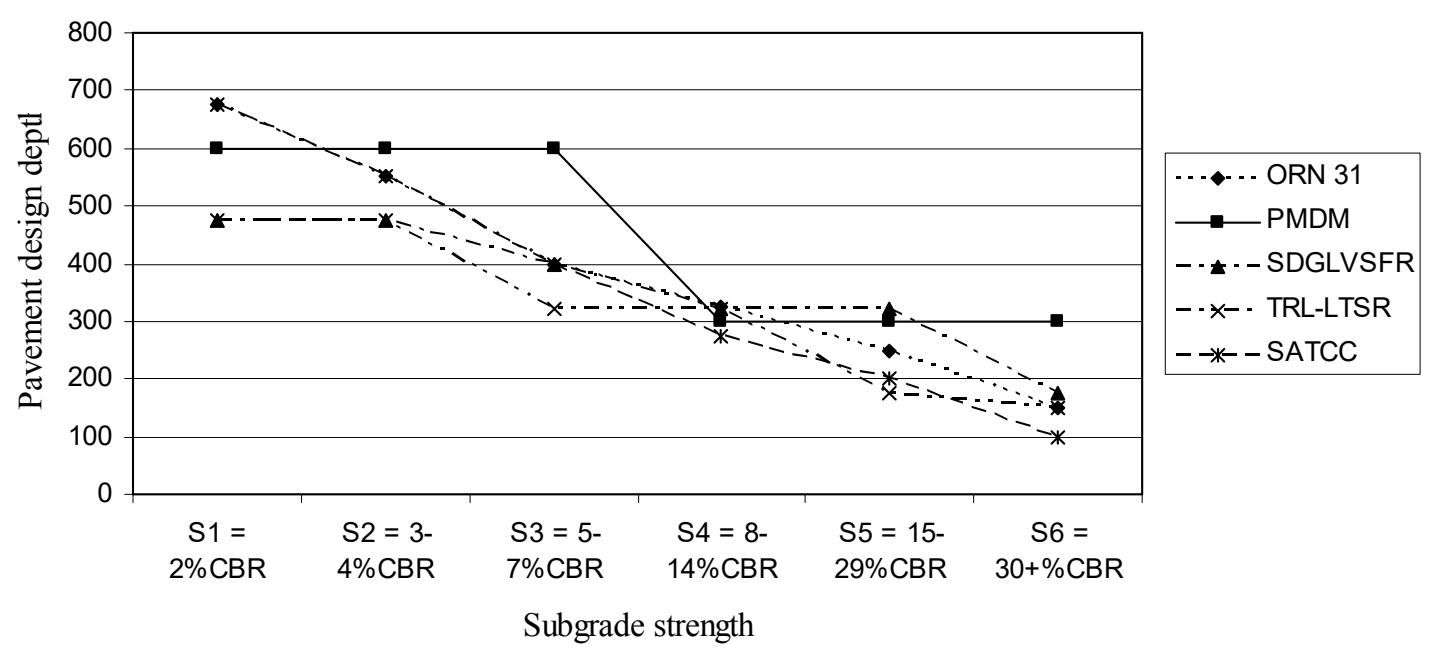

Figure 4: Pavement design depths for different design standards

The analysis of design depths shown in figure 4 suggests that for most subgrade classes, less construction materials will be used when the TRL developed design method for lightly trafficked sealed roads in southern Africa (TRL-LTSR) is used, followed by SDGLVSFR, SATCC, ORN 31 and lastly PMDM. Therefore more construction materials will be required when designing LVSRs using PMDM compared with the rest of the design methods.

\subsection{Construction Costs Comparison}

The subsequent analysis of the resulting costs has been shown in table 5 and figure 5 with the TRL method for lightly trafficked roads in southern Africa (TRL-LTSR) resulting in lowest cost. Surface seals of Otta and surface dressing are relatively cheaper compared with asphalt concrete (AC) layer, the Otta seal being the cheapest.

Table 5: Pavement construction costs (Tshs) per km for the three types of surfacing

\begin{tabular}{|l|c|c|r|r|c|}
\hline S/Layer & ORN 31 & PMDM & SDGLVSFR & TRL-LTSR & SATCC \\
\hline \hline Otta seal & $177,500,000$ & $220,500,000$ & $179,000,000$ & $153,400,000$ & $177,500,000$ \\
\hline S/dressing & $207,500,000$ & $250,500,000$ & $209,000,000$ & $183,000,000$ & $207,500,000$ \\
\hline AC layer & $482,500,000$ & $525,500,000$ & $484,000,000$ & $458,400,000$ & $482,500,000$ \\
\hline
\end{tabular}




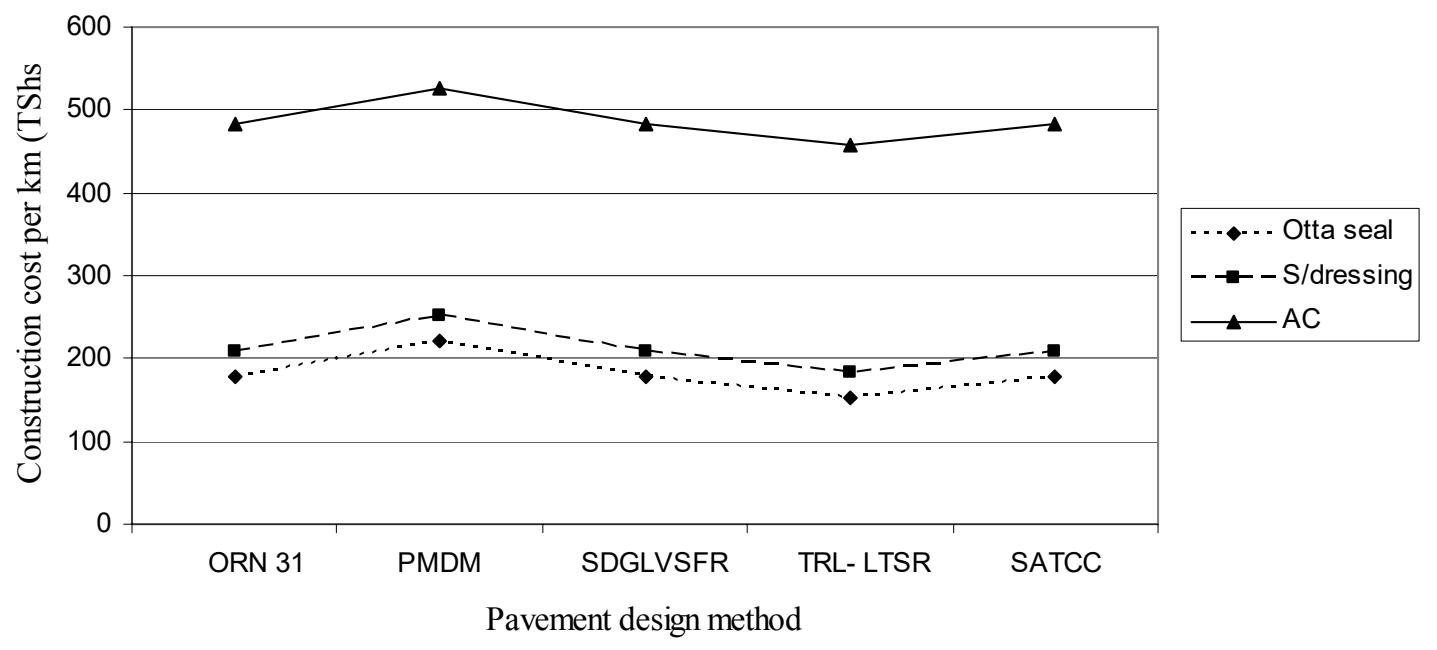

Figure 5: Pavement construction costs for different design methods

Further analysis was also carried out on construction costs for existing pavements as designed using conventional methods in Tanzania using PMDM and when designed using the most cost-effective TRL-LTSR method for pavements of 144 roads with a total length of $240.7 \mathrm{~km}$ and having fifteen (15) different types of designed pavement structures. The result of this analysis shows that, constructing $240.7 \mathrm{~km}$ of existing pavement as conventionally designed in Tanzania results in construction cost of Tshs 425,735,290 per km, while if the pavements were designed using methods meant for LVSRs such as TRL-LTSR, the resulting cost is Tshs 208,502,545 per km. This results in total savings of Tshs $217,232,745$ per $\mathrm{km}$ which is equivalent to $51 \%$ cost saving per $\mathrm{km}$ when LVSRs are designed as such.

\subsection{Development of Definition for LVSR in Tanzania}

The criterion for defining a low volume road varies significantly in various parts of the world. In the SADC region, LVSRs typically carry less than 200 vpd including up to $20 \%$ commercial vehicles and often include NMT, particularly near populated areas. Investigations carried out in SADC region show that the large proportion of LVSR carry typically less than 0.5 million ESA over their design life and that traffic below 0.3 to 0.5 million ESA was not a significant factor in pavement deterioration (SATCC 2003). In overseas especially USA and UK the upper limit for traffic volume for LVSRs in most cases varies from 400 to 500 vehicles per day. Aspects of the Low-volume Sealed Roads are not explicitly specified in the Tanzanian guide for pavement design (PMDM). There is thus no clear definition of what is a LVSR in Tanzania.

The cumulative number of standard axles, E80 with various values of ADT and design periods of 10,15 and 20 years were computed. The resulting values of E80 compared with the 0.5 million ESA limit recommended for LVSRs are shown in table 6 . The results suggest that the designed LVSR pavement will perform satisfactorily when loaded with traffic volume of ADT of up to $500 \mathrm{vpd}$ for a period of 10 years, and ADT of up to $400 \mathrm{vpd}$ for a period of 15 years while to survive for a period of 20 years the pavement can only support $200 \mathrm{vpd}$, as shown in table 6 and figure 6. 
Table 6: Comparison of E 80 Design for different traffic volumes of low volume roads

\begin{tabular}{|c|c|c|c|c|c|c|c|c|c|c|c|c|}
\hline 客 & 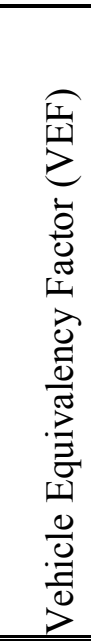 & 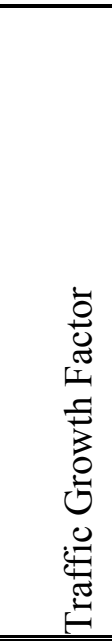 & 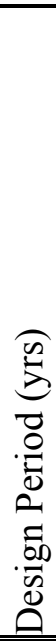 & 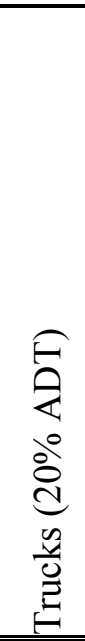 & 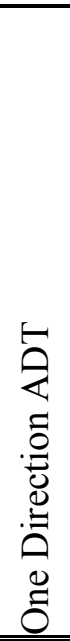 & 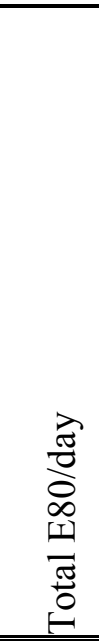 & 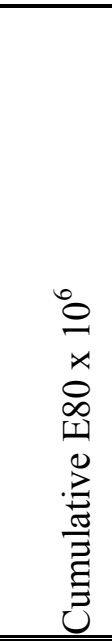 & 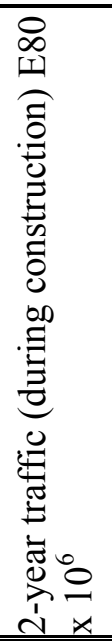 & 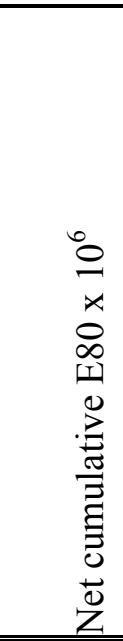 & 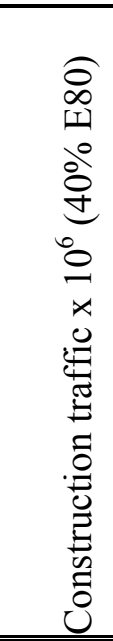 & 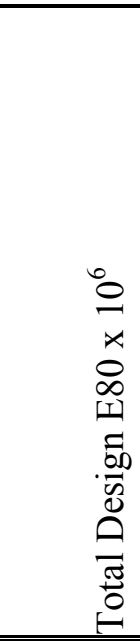 & 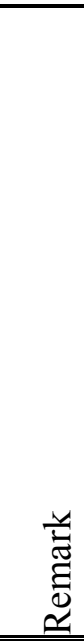 \\
\hline & & & & & & & A & $\mathrm{B}$ & $\begin{array}{c}\mathrm{C}=\mathrm{A}- \\
\mathrm{B}\end{array}$ & $\mathrm{D}$ & $\mathrm{E}=\mathrm{C}+\mathrm{D}$ & \\
\hline 200 & 1.06 & 0.047 & 10 & 40 & 20 & 21.2 & 0.121 & 0.016 & 0.105 & 0.042 & 0.147 & $<0.5$ \\
\hline 300 & 1.06 & 0.047 & 10 & 60 & 30 & 31.8 & 0.182 & 0.024 & 0.158 & 0.063 & 0.221 & $<0.5$ \\
\hline 400 & 1.06 & 0.047 & 10 & 80 & 40 & 42.4 & 0.242 & 0.031 & 0.211 & 0.084 & 0.295 & $<0.5$ \\
\hline 500 & 1.06 & 0.047 & 10 & 100 & 50 & 53.0 & 0.303 & 0.04 & 0.263 & 0.105 & 0.368 & $<0.5$ \\
\hline 200 & 1.06 & 0.047 & 15 & 40 & 20 & 21.2 & 0.195 & 0.016 & 0.179 & 0.072 & 0.251 & $<0.5$ \\
\hline 300 & 1.06 & 0.047 & 15 & 60 & 30 & 31.8 & 0.292 & 0.024 & 0.268 & 0.107 & 0.375 & $<0.5$ \\
\hline 400 & 1.06 & 0.047 & 15 & 80 & 40 & 42.4 & 0.390 & 0.032 & 0.358 & 0.143 & 0.501 & $=0.5$ \\
\hline 500 & 1.06 & 0.047 & 15 & 100 & 50 & 53.0 & 0.487 & 0.04 & 0.447 & 0.179 & 0.626 & $>0.5$ \\
\hline 200 & 1.06 & 0.047 & 20 & 40 & 20 & 21.2 & 0.288 & 0.016 & 0.272 & 0.109 & 0.381 & $<0.5$ \\
\hline 300 & 1.06 & 0.047 & 20 & 60 & 30 & 31.8 & 0.431 & 0.024 & 0.407 & 0.163 & 0.570 & $>0.5$ \\
\hline 400 & 1.06 & 0.047 & 20 & 80 & 40 & 42.4 & 0.575 & 0.031 & 0.544 & 0.217 & 0.761 & $>0.5$ \\
\hline 500 & 1.06 & 0.047 & 20 & 100 & 50 & 53.0 & 0.719 & 0.040 & 0.679 & 0.272 & 0.951 & $>0.5$ \\
\hline
\end{tabular}

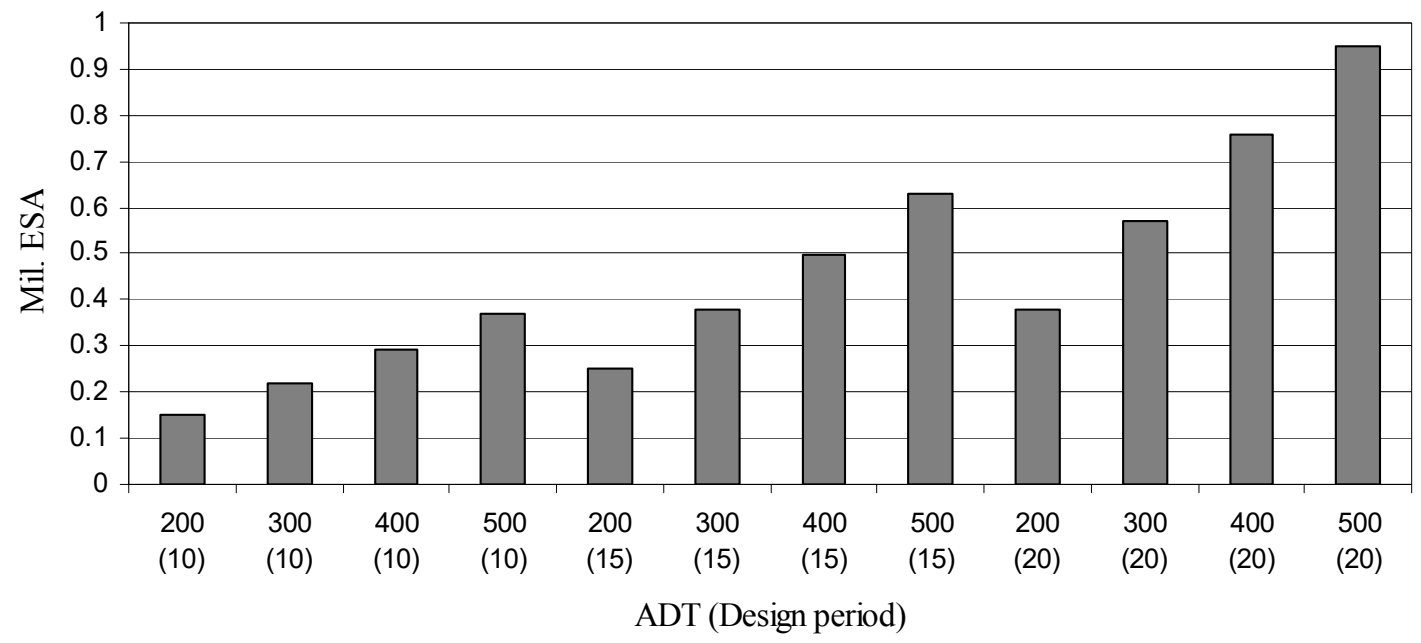

Figure 6: Relationships between ESA, ADT and design period 
The analysis shows that a LVSR pavement may be considered safe against traffic loading for a maximum of $400 \mathrm{vpd}$ for a design period of 15 years provided the conditions for heavy vehicles are met. SADC guideline on low volume sealed roads specifies a design period of 15 - 20 years only when both the design data reliability and road importance are high, something which would rarely occur in the case of LVSRs and even when it does, 15 years is still acceptable. Hence, the definition for a LVSR in Tanzania may thus be expressed as "Regional and district roads carrying less than 400 vehicles per day, of which up to $20 \%$ may be commercial vehicles not exceeding medium goods vehicle category".

\subsection{Conclusion and Recommendations}

\subsection{Conclusion}

- The unnecessarily high construction costs currently associated with LVSRs call for the development of design guidelines and procedures for LVSR in Tanzania in place of the existing Pavement and Material Design Manual (PMDM), which is inappropriate for LVSRs.

- It has been possible to study LVSRs and come up with a cost-effective pavement design method for LVSRs in Tanzania through the analysis and comparison of five pavement design methods recommended by SADC guideline on low-volume sealed roads (LVSRs). The TRL developed method for lightly trafficked sealed road in southern Africa (TRL-LTSR) has been found to be the most costeffective.

- Construction cost comparison made between the TRL method for Lightly Trafficked Sealed Road in southern Africa (TRL-LTSR) and the conventional method in Tanzania that uses the Pavement and Material Design Manual (PMDM) revealed that there is substantial cost saving of about $51 \%$ when the LVSR is designed using specially developed method for LVSRs such as the TRLLTSR than using PMDM method.

- The traffic loading analysis on LVSR has shown that LVSR can accommodate up to $400 \mathrm{vpd}$ for a design life of 15 years, while about 200 vpd can be accommodated for 20 years with traffic consisting of $20 \%$ medium goods vehicle.

- It has become obvious that the use of asphalt concrete (AC) as surfacing on low-volume roads in Tanzania results in high construction costs and should be discouraged. Results show Otta seal and surface dressing to be cheaper options for sealing LVSRs, with Otta seal being the cheapest.

\subsection{Recommendations}

- Application of appropriate technical standards and design methods for the LVSRs pavement is critical if costeffective and sustainable solutions are to be obtained. Time has come for all road authorities in Tanzania to adopt and make use of the results of this study and move away from using conventional standards of pavement design and develop special procedures for the design of LVSRs.

- The TRL developed pavement design method for "Lightly trafficked sealed roads in southern Africa" has demonstrated to be the most costeffective when applied in designing LVSRs in Tanzania. Much attention should be given to this method by all road stakeholders when designing and developing pavement design standards for LVSRs in Tanzania.

- With respect to the findings of this study, the definition for a lowvolume sealed road in Tanzania is recommended to be "regional and district roads carrying not more than 400 vehicles per day, of which up to 
$20 \%$ may be commercial vehicle not exceeding medium goods vehicle category". This assumes a design period of 15 years which is considered to be more relevant for LVSRs.

\section{REFERENCES}

1. Benmaamar, M. A Method for the Appraisal of Low-Volume Roads in Tanzania. TRL, Crothorne, UK. 2003.

2. Gourley, C. S. Lightly Trafficked Sealed Roads in Southern Africa. TRL, Crowthorne, Berkshire RG45 6AU, U.K. 1997.

3. Gourley, C. S. and Greening, P. A. K. A Performance of Low-Volume Sealed Roads: Results and Recommendations for Studies in Southern Africa. TRL Published Report PR/OSC/167/99. Crowthorne. 1999.

4. Gourley, C. S., Greening, P. A. K. and Bruders, U. A Structural Design Guide for Low Volume Secondary and Feeder Roads in Zimbabwe. TRL, Crowthorne, Berkshire RG45 6AU, U.K. 1998.
5. Gourley, C.S., Toole, T., Morosiuk, G. and Hine. J.L. Cost Effective Design for Low Volume Sealed Roads in Tropical and Subtropical Countries. United Kingdom. 2001.

6. Ministry of Works (MoW), Tanzania. Pavement and Material Design Manual, Dar es Salaam. 1999.

7. Southern Africa Transport and Communication Commission (SATCC). Code of Practice for the Design of Road Pavements (draft). Division of Roads and Transport Technology, CSIR. 1998.

8. Southern Africa Transport and Communication Commission (SATCC). SADC Guideline on Low-Volume Sealed Roads. Gaborone. Botswana. 2003.

9. Transport Research Laboratory (TRL). Overseas Road Note 31. A Guide to the Structural Design of Bitumen-Surfaced Roads in Tropical and Sub-Tropical Countries. TRL. $4^{\text {th }}$ edition. Crowthorne. Berkshire, U.K. 1993. 